\title{
Respiration Rates of Organic Soil Depending on Changes of Moisture and Aeration
}

\author{
Zofia Fischer $^{1 *}$, Pavel Blažka ${ }^{2 \#, ~ L i d y a ~ D u b i s ~}{ }^{1}$ \\ ${ }^{1}$ Faculty of Mathematics, Informatics and Landscape Architecture, John Paul II, Catholic University of Lublin, Lublin, Poland \\ ${ }^{2}$ Department of Science, University of South Bohemia, České Budějovice, Czech \\ Email: *zofiaf@plusnet.pl, lida.dubis@gmail.com
}

How to cite this paper: Fischer, Z., Blažka, P. and Dubis, L. (2017) Respiration Rates of Organic Soil Depending on Changes of Moisture and Aeration. Open Journal of Soil Science, 7, 101-110.

https://doi.org/10.4236/ojss.2017.76008

Received: May 4, 2017

Accepted: June 4, 2017

Published: June 7, 2017

Copyright $\odot 2017$ by authors and Scientific Research Publishing Inc. This work is licensed under the Creative Commons Attribution International License (CC BY 4.0).

http://creativecommons.org/licenses/by/4.0/

(c) (i) Open Access

\begin{abstract}
This paper aims at analyzing changes in soil respiration depending on the levels of soil moisture and aeration. Organic forest soil was used in the experiments. Watering of the soil was applied starting from two initial moisture contents: 1) GWC $>0.1$, desiccated soil, respiration equals to zero; 2) GWC between $0.46-0.78$, moisture of the soil approximately the same as at the time of sample collection. Watering of the soil was applied once or continuously during the experiment. The experiments were conducted under both: unrestricted air-supply and anoxic conditions. Measurements of: oxygen consumption, carbon dioxide emission, and RQ were determined with a volumetric respirometer. Soil desiccation, which occurs under good access of the air, and leads to the increase of respiration rate (the "Birch effect"), is predominantly related to aerobic respiration following the change in soil aeration. If respiration of non-desiccated soil is assumed as $100 \%$, the oxygen consumption of desiccated soil equaled to $209.90 \%$ of such value in the non-desiccated soil at the lowest moisture level, and only to $51 \%$ at the highest. Carbon dioxide emission equaled to $191.92 \%$ and $111 \%$ at the lowest and the highest moisture levels, respectively. Desiccation did not increase the respiration rate under anoxic conditions. It either decreased or remained statistically unchanged. However, obtained values of RQ index suggest that under anoxic conditions desiccation affects fermentation processes in the soil. The value of RQ index at the moisture level lower than GWC 1 was very low attaining merely $0.3-0.4$, which suggests active fermentation processes. At higher moisture content yet, RQ value exceeded 2 .
\end{abstract}

\section{Keywords}

Birch Effect, Anoxia, RQ, Watering 


\section{Introduction}

The authors of the study analyzed a respirometric reaction of organic soil for changes of its moisture. In the preceding paper, the respirometric reactions of the soil to desiccation were evaluated [1]. Under natural conditions, the process of drying out interlinks with an increase of moisture contents, therefore we hope that both papers are complementary.

According to IPCC (Intergovernmental Panel on Climate Change) assessments, in the forthcoming years, summer period will become hotter even in temperate regions, with ambient temperatures reaching $35^{\circ} \mathrm{C}$ or even $40^{\circ} \mathrm{C}$. Therefore several week-long periods of drought can be expected. The distribution of precipitation will also change, especially in the summer. Rains will become rare but torrential, causing drastic changes in the soil moisture. Thus, a response of decomposition and mineralization rate, as well as carbon dioxide emission to various levels of watering or even waterlogging of the soil becomes an important issue for various climate zones.

Already in the sixties of the last century, Birch et al. [2] [3] proved that postdrought organic matter decomposition increases considerably after rewetting. The phenomenon is commonly known as the Birch effect. Classic Birch's studies [2] [4] were to trace decomposition in tropical climates in fields exposed to alternate drought and precipitation. The experiments indicated that soil drying and wetting cycles stimulate organic matter mineralization. It was emphasized in the next studies that trees, their root systems as well as the quantity and quality of organic substances play a crucial role in the process [5] [6]. The causes of the Birch effect, however, are not fully understood. It is said that the Birch effect results from the rapid growth of microorganisms and fungal biomass [3] or a greater availability of respiration substrates coming from organisms, which died in the previous drought [7]. However, the last hypothesis was not fully proven and Birch himself, taking such a possibility into account, withdrew from that hypothesis in his following studies. One thing that all those studies point to as to something important, is the "moisture content record" of the soil exposed to watering.

If rewetting stimulates mineralization, it is understandable that it also enhances both: soil respiration and fermentation. The key issue for the whole ecosystem is the ratio between the degree to which soil moisture content influences soil respiration and the degree to which it influences the fermentation. Adopted by us the respirometric method is based on recording the volumes of emitted carbon dioxide and consumed oxygen. The method also allows us to determine the RQ index, which, to some extent, estimates the role of fermentation and respiration in the respired soil. This determination, though, is not too accurate as $\mathrm{RQ}$ rate can range from over 1 to below 0.7 depending on particular fermentation pathways [1]. The major concern, however, is whether experiments are conducted under unrestricted air-supply conditions, as in most laboratory studies, or under conditions more similar to those in nature where oxygen deficiency may occur. 
Soil metabolism under anoxic conditions has rarely been studied, primarily due to methodological difficulties. It can be assessed in two ways, in the field and in the laboratory [8] [9]. Field studies most often rely on the amount of carbon dioxide emitted from the soil surface. Although these studies present an actual state at a particular time period and site, an inability to isolate the causes of the observed phenomena makes an accurate interpretation of the results difficult. This is due to an excessive number of unrecorded, variable factors. Laboratory methods record the majority of acting factors, they cannot, however, be directly transferred to natural conditions. The methodology of laboratory studies requires disturbing the soil, destroying its original structure as well as oxygenating and sieving it while taking a sample. The experiments presented in this paper were conducted under laboratory conditions, including both the deficit and unrestricted oxygen-supply.

The aim of this paper is to analyze changes in soil respiration caused by various watering patterns. Initial moisture content, aeration and subsequent watering schedule were taken as variables.

\section{Material and Methods}

\subsection{The Site and Soil Sampling}

Soil samples were collected from mixed forest situated in central Poland, $\left(52^{\circ} 20^{\prime} 212 \mathrm{~N}, 020^{\circ} 51^{\prime} 260 \mathrm{E}\right)$, at elevation of $81 \mathrm{~m}$ above sea level. The climate of the area is mild, changing in particular years between Atlantic and more continental type. Mean annual temperature for year 2016 was $9.18^{\circ} \mathrm{C}$, and annual precipitation was $529 \mathrm{~mm}$ (Polish meteo service: www.weatheronline.pl). Soil samples were collected in a mature mixed stand with canopy closure of $100 \%$. Dominant tree species there were: alder-Alnusglutinosa (L.), oak-Quercusrobur L., horn beam-Carpinusbetulus L., pine-Pinussylvestris L., birchBetula pendula Roth., maple-Acer platanoides L. The soil type there is a histosol. The site was described in detail by Blažka and Fischer [10]. This soil was used as the material for laboratory experiments, not as the soil characteristic for a specific site. Soil samples were taken from the soil A1 layer, at a depth of about $10 \mathrm{~cm}$, sieved through a $5 \mathrm{~mm}$ sieve, following suggestions by Carter and Gregorich [11]. The soil was highly organic, nearly 50\% LOI, sand constituting the majority of mineral fraction.

\subsection{Laboratory Analyses}

\subsubsection{Humidity}

(GWC-gravimetric water content, WHC-water holding capacity, dm-dry mass.) Our procedure was based essentially on Grace et al., Priha and Smolander [12] [13] with minor modifications [10]. GWC and other contents are given as ratios, but not \%. Dry mass was determined by drying at $110^{\circ} \mathrm{C}$ to constant weight.

\subsubsection{Soil Organic Matter (SOM)}

SOM was estimated as loss of weight in ignition to constant weight (LOI) at 
$500^{\circ} \mathrm{C}$ on selected samples.

\subsubsection{Respiration}

(OCD—oxygen consumption, $\mathrm{PCO}_{2}$ - production of $\mathrm{CO}_{2}, \mathrm{RQ}$-respiratory quotient.)

We used the volumetric method with the Scholander type respirometer to get both the oxygen consumption and carbon dioxide production [14]. Each experimental series consisted of two parts. In the first, without hydroxide in the flasks, changes in the volumes were recorded mostly for 5 hours, this gave the sum of $\mathrm{CO}_{2}$ changes and $\mathrm{O}_{2}$ consumption, in the second part after placing filter paper soaked with $\mathrm{NaOH}$ solution into the respirometric chamber, we recorded the oxygen consumption (OCD) for another 5 hours interval, readings each 30 minutes. The bath temperature was $17.0^{\circ} \mathrm{C}$.

We then plotted the results against time of readings, the slope coefficient of the regression $(\beta 1)$ was the rate $\left(\mathrm{O}_{2}\right.$ consumption-OCD or $\left.\mathrm{PCO}_{2}\right)$; the respective regression coefficients were all $\mathrm{r}>0.95$, they were later corrected for pressure and temperature, multiplied by the calibration factor and related per gram dry soil and hour. The method was described in detail by Fischer and Blažka [1].

\subsection{Experimental}

There were three key experiments in the study (Mc, Ma, Ms). The experiments differed in: 1) the initial moisture content, 2) the air supply (unrestricted and anoxic), 3) the watering pattern (one-time or repeated).

Initial moisture content. Two different levels of initial soil moisture were used in the study: the first was the actual moisture of the soil directly after taking it from the field, so the moisture content values varied in separate experiments from GWC 0.46 to 0.78 . The second initial moisture level was that of the desiccated soil, where GWC $<0.1$ and respiration was equal to 0 .

Air supply. Air supply to the soil was assumed to be good when the container was filled up to $1 / 3$ of the volume with the soil and it was not compressed. Dry mass of the sample ranged from 4.23 to $6.38 \mathrm{~g}$, depending on moisture content. Oxygen supply was assumed to be in deficiency when the whole container was filled up with the soil and the soil was maximally compressed. Dry mass of these soil samples ranged from 32.8 to $36.6 \mathrm{~g}$.

Wattering. The soil was watered once or continuously during the experiment. The same amount of water was supplied every 4 days in continuous watering. Respirometric measurements were taken a day before each supplementation of the water. In one-time watering pattern respirometric containers were filled up with dried or wet soil, depending on the experiments, then samples were watered up to desired moisture level, and measurements were performed on the fourth day.

Table 1 shows the scheme of conditions applied in particular experiments. In the series of MC and MS trials, GWC was increased by about 0.5 , following each watering while in the MA series approximately by 0.2 . In MS and MA trials, 
Table 1. Scheme of experiments (Mc, Ms, Ma) conducted under various regimes of air access (unrestricted or anoxic), input of water (one-time or repeated), and initial value of GWC.

\begin{tabular}{cccc}
\hline Conditions $\backslash$ Experiment & Mc & Ms & Ma \\
\hline Unrestricted air access & $\mathrm{X}$ & $\mathrm{X}$ & $\mathrm{X}$ \\
Deficit of air & & & \\
Repeated watering & $\mathrm{X}$ & & $\mathrm{X}$ \\
One time watering & & $\mathrm{X}$ & $\mathrm{X}$ \\
Different initial GWC & $\mathrm{X}$ & $\mathrm{X}$ & \\
\hline
\end{tabular}

respiration was additionally measured in 24 hours after supplementation of the water to confirm the stabilization of respiration rate.

GWC and WHC were determined after each trial. Respiration rate was determined in 6 replicates.

\subsection{Statistics}

Means (m), standard deviations (s), coefficients of variation (cv) and standard errors of the mean (se) were determined for all data series. T-test for equality of means was used to determine the statistical significance of mean differences.

\section{Results and Discussion}

\subsection{Unrestricted Air Access}

The MC and MS trial, as described in the methods (Table 1) was carried out on uncompressed soil, only in partially filled up respirometric containers. Sieving, necessary to uniform soil samples, facilitates an influx of greater amounts of air into the soil, the release of $\mathrm{CO}_{2}$ previously accumulated into the atmosphere [1] or even a change in soil granulometry [15]. Sieved soil placed into containers exposed to the air can be compared to surface layers of the soil.

The analysis of results of Mc experiment in which continuous watering was applied to samples with two different levels of moisture content (GWC 0.78 and GWC 0.1) revealed, that oxygen consumption of the desiccated soil (GWC 0.1) was higher than that of the non-desiccated soil over the whole period of the experiment (36 days) (Table 2). Only after the soil reached its moisture content (GWC) equal to 2.09 , during the highest intensity of metabolism, differences between the series were statistically insignificant. Carbon dioxide emission was also higher in B series (Table 2), but the differences were not always statistically significant. The RQ index did not differ in both series in most of moisture regimes. This implies that supplementation of the water to the desiccated (partially dead) soil created better conditions for metabolic processes than in an active wet soil. This result was attributed to the Birch effect [2] [16]. Despite a regular (every 4 days) watering and the soil becoming increasingly wetter the effect of its initial dessication was still visible (Table 2). This result supports the theory that a spontaneous microbial and fungal hyphae biomass growth takes place after desiccation [16]. Additionally, it is also possible that wetting of desiccated soil 
Table 2. A comparison of oxygen consumption rate (OCD), the rate of $\mathrm{CO}_{2}$ production $\left(\mathrm{PCO}_{2}\right)\left(\right.$ as $\left.\mu l \cdot g[\mathrm{dm}]^{-1} \cdot \mathrm{h}^{-1}\right)$ and RQ values in Mc experiment involving two variants of initial soil humidity: A-GWC 0.781; B-GWC 0.1, with constant watering of soil samples. P-significance of differences between means (a two-sample location test).

\begin{tabular}{cccccccccc}
\hline GWC & OCD A & OCD B & $\mathrm{P}$ & $\mathrm{PCO}_{2} \mathrm{~A}$ & $\mathrm{PCO}_{2} \mathrm{~B}$ & $\mathrm{P}$ & $\mathrm{RQA}$ & $\mathrm{RQB}$ & $\mathrm{P}$ \\
\hline & Mean; SE & Mean; SE & & Mean; SE & Mean; SE & & Mean; SE & Mean; SE \\
\hline 0.78 & $3.853 ; 0.112$ & $5.201 ; 0.240$ & 0.000 & $3.003 ; 0.082$ & $3.976 ; 0.207$ & 0.001 & $0.779 ; 0.027$ & $0.764 ; 0.015$ & 0.503 \\
1.141 & $3.608 ; 0.068$ & $7.188 ; 0.409$ & 0.000 & $2.740 ; 0.150$ & $5.936 ; 0.448$ & 0.000 & $0.759 ; 0.020$ & $0.825 ; 0.020$ & 0.174 \\
1.583 & $3.610 ; 0.097$ & $4.680 ; 0.491$ & 0.001 & $2.825 ; 0.141$ & $3.168 ; 0.123$ & 0.097 & $0.782 ; 0.027$ & $0.676 ; 0.008$ & 0.009 \\
2.019 & $4.370 ; 0.148$ & $4.590 ; 0.183$ & 0.374 & $3.101 ; 0.143$ & $3.283 ; 0.151$ & 0.404 & $0.709 ; 0.031$ & $0.715 ; 0.018$ & 0.828 \\
2.683 & $2.336 ; 0.122$ & $3.235 ; 0.304$ & 0.021 & $2.503 ; 0.127$ & $3.235 ; 0.304$ & 0.051 & $1.071 ; 0.034$ & $1.000 ; 0.000$ & 0.139 \\
3.023 & $1.843 ; 0.078$ & $2.700 ; 0.341$ & 0.000 & $2.321 ; 0.165$ & $3.216 ; 0.097$ & 0.001 & $1.259 ; 0.068$ & $1.191 ; 0.068$ & 0.179 \\
\hline
\end{tabular}

makes previously inaccessible substrates available. An increase in metabolic activity may be related to both the multiplication of organisms and the restoration/activation of respiratory mechanisms in the organisms previously adapted to drought.

WHC (water holding capacity) measurements were taken at the end of the experiment. The measurements revealed the significance of WHC mean differences in the desiccated and non-desiccated soil series at the level ( $\mathrm{t}$-Test groups) of $p=0.034$. This may suggest that desiccation affects the quality of organic substances in the soil [10].

The comparison of metabolism in one time watered, dessicated and naturally wet soils (Ms trials, Table 3) yielded similar results, i.e. a higher respiration of the desiccated soil. This suggests that irrespectively of whether water is supplemented once or continuously, it is the level of desiccation of the soil that matters in the course of metabolism.

Following the supplementation of subsequent amounts of water i.e. during reaching higher levels of soil moisture, its respiration increased in Ms A series, while the respiration of desiccated soil (Ms B) decreased. If respiration of nondesiccated soil is assumed as $100 \%$, the oxygen consumption of desiccated soil equaled to $209.90 \%$ of such value in the non-desiccated soil at the lowest moisture level, and only $51 \%$ at the highest. Carbon dioxide emission equaled to $191.92 \%$ and $111 \%$ at the lowest and the highest moisture levels, respectively. Its consequence was the increase of the RQ index up to 1 in the desiccated soil, while in the non-desiccated soil it ranged from 0.7 to 0.8 (Table 3).

Hence, one can hypothesize that desiccation primarily stimulates aerobic respiration. Non-desiccated soil reacts to supplementation of the water with increased respiration. With increasing moisture, aerobic respiration is suplemented by fermentation. At low levels of moisture, i.e. when the soil is well-aerated and aerobic respiration optimized, desiccation is the strongest determinant of respiration. The higher water content in the soil, and thereby a restricted supply of oxygen for aerobic respiration, the less pronounced is the Birch effect's impact.

In conclusion, it should be stated that not only the final moisture content but 
Table 3. A comparison of oxygen consumption rate (OCD), the rate of $\mathrm{CO}_{2}$ production $\left(\mathrm{PCO}_{2}\right)\left(\right.$ as $\left.\mu \mathrm{l} \cdot \mathrm{g}[\mathrm{dm}]^{-1} \cdot \mathrm{h}^{-1}\right)$ and RQ values in Ms experiment involving two variants of initial soil humidity: A-GWC 0.466; B-GWC 0.06 with constant watering of soil samples. P-significance of differences between means (a two-sample location test).

\begin{tabular}{cccccccccc}
\hline GWC & OCD A & OCD B & P & $\mathrm{PCO}_{2} \mathrm{~A}$ & $\mathrm{PCO}_{2} \mathrm{~B}$ & $\mathrm{P}$ & $\mathrm{RQA}$ & $\mathrm{RQB}$ \\
\hline Range & Mean ;SE & Mean; SE & & Mean; SE & Mean; SE & & Mean; SE & Mean; SE \\
\hline $0.57-0.66$ & $3.251 ; 0.237$ & $6.826 ; 0.354$ & 0.000 & $2.611 ; 0.277$ & $5.013 ; 0.312$ & 0.000 & $0.790 ; 0.043$ & $0.732 ; 0.011$ & 0.230 \\
$0.79-0.94$ & $3.388 ; 0.249$ & $5.733 ; 0.207$ & 0.000 & $2.835 ; 0.198$ & $4.018 ; 0.167$ & 0.001 & $0.843 ; 0.038$ & $0.701 ; 0.023$ & 0.011 \\
$1.17-1.18$ & $3.902 ; 0.175$ & $4.982 ; 0.693$ & 0.162 & $3.001 ; 0.167$ & $4.629 ; 0.743$ & 0.058 & $0.772 ; 0.011$ & $0.811 ; 0.018$ & 0.098 \\
$1.42-1.43$ & $3.922 ; 0.275$ & $4.656 ; 0.292$ & 0.097 & $2.811 ; 0.313$ & $3.816 ; 0.263$ & 0.032 & $0.712 ; 0.040$ & $0.823 ; 0.015$ & 0.090 \\
$1.59-1.60$ & $4.444 ; 0.192$ & $2.273 ; 0.061$ & 0.000 & $3.431 ; 0.196$ & $2.273 ; 0.061$ & 0.000 & $0.770 ; 0.018$ & $1.000 ; 0.000$ & 0.000 \\
\hline
\end{tabular}

also an initial state of desiccation of the soil that is supplemented with water, are important for metabolic processes of the surface, to some extent aerated, layer of the soil. Desiccation increases soil respiration rates so substantially that respiration is statistically higher than of the non-desiccated soil even after 30 days of constant watering. The obtained results indicate that the increase of the respiration rate after watering of desiccated soil can be primarily related to aerobic respiration, which suggests that it results not from the change in moisture level but from the alteration of soil aeration.

\subsection{Deficit of Air}

As it was mentioned in the Introduction, mainly because of methodological difficulties, the studies concerning the metabolism of deeper soil layers being under anoxia are unique. Such studies have been rather focused on a variety of processes under anoxia e.g. in peatlands. The method applied in the present study is an attempt of oxygen deficiency simulation, i.e. the conditions similar to those of soil layers below its surface. The results of the measurements which were conducted under oxygen deficiency (experiment $\mathrm{Ma}$ ) differ significantly from the results obtained under unrestricted air-supply conditions (Table 4). Respiration measured under unrestricted oxygen-supply conditions has always been higher than under oxygen deficiency. It is understandable, since respiration is more effective than fermentation, which is a dominating process under anoxia. Under oxygen deficiency, at low moisture levels $(\mathrm{GWC}<1)$, when some amounts of air in the soil remain not replaced yet by the water, $\mathrm{RQ}$ is below $0.5 . \mathrm{CO}_{2}$ emission may result partially from respiration and partially from fermentation, e.g. the transformation of lactic acid to ethanol. At higher moisture levels (GWC > 1), $\mathrm{RQ}$ value increases sharply which is the result of a drastic decrease in the quantity of oxygen used. At the moisture level of GWC ranging from 1.17 to 1.22, under the oxygen deficiency, the amount of oxygen used then equals to only $6.6 \%$ of the oxygen used under unrestricted air-supply conditions, while the amount of produced carbon dioxide equals to $16.9 \%$. This suggests an enhancement of fermentation processes, which do not use oxygen. Those processes in the soil have a character of chain reaction and they are not necessarily directly reflected in gaseous processes. Fermentation may neither induce a production of carbon 
Table 4. A comparison of the rate of oxygen consumption (OCD), production of carbon dioxide $\left(\mathrm{PCO}_{2}\right)\left(\right.$ as $\left.\mu \mathrm{l} \cdot \mathrm{g}[\mathrm{dm}]^{-1} \cdot \mathrm{h}^{-1}\right)$ and RQ values obtained in experiments Ma and Ms with single watering of soil samples for two different variants of air access: A-full air access, B-a deficit of air access. Initial humidity GWC 0.5. P-significance of differences between means.

\begin{tabular}{|c|c|c|c|c|c|c|c|c|c|}
\hline GWC & OCD A & OCD B & $\mathrm{P}$ & $\mathrm{PCO}_{2} \mathrm{~A}$ & $\mathrm{PCO}_{2} \mathrm{~B}$ & $\mathrm{P}$ & RQ A & RQ B & $\mathrm{P}$ \\
\hline range & Mean; SE & Mean; SE & & Mean; SE & Mean; SE & & Mean; SE & Mean; SE & \\
\hline $0.47-0.52$ & $5.778 ; 0.210$ & $2.704 ; 0.335$ & 0.000 & $4.201 ; 0.271$ & $1.437 ; 0.330$ & 0.000 & $0.726 ; 0.043$ & $0.437 ; 0.103$ & 0.037 \\
\hline $0.66-0.97$ & $3.251 ; 0.237$ & $1.450 ; 0.046$ & 0.000 & $2.611 ; 0.277$ & $0.511 ; 0.143$ & 0.000 & $0.760 ; 0.043$ & $0.357 ; 0.103$ & 0.005 \\
\hline $0.97-1.03$ & $3.388 ; 0.249$ & $0.373 ; 0.071$ & 0.000 & $2.835 ; 0.198$ & $0.761 ; 0.121$ & 0.000 & $0.843 ; 0.038$ & $2.238 ; 0.238$ & 0.000 \\
\hline $1.50-1.59$ & $3.574 ; 0.188$ & $0.000 ; 0.000$ & 0.000 & $2.64 ; 0.207$ & $0.000 ; 0.000$ & 0.000 & $0.737 ; 0.019$ & & \\
\hline $1.94-2.00$ & $3.574 ; 0.188$ & $0.000 ; 0.000$ & 0.000 & $2.640 ; 0.207$ & $0.000 ; 0.000$ & 0.000 & $0.732 ; 0.019$ & & \\
\hline
\end{tabular}

dioxide nor an oxygen consumption. Respiration decreases to zero under oxygen deficiency conditions, at the moisture of the soil at the level GWC 1.5 and higher.

The respiration rate of previously desiccated soil is different under oxygen deficiency (Table 5). Desiccation affects respiration, however, in a different way compared with the soil having good access to oxygen. At the lowest moisture levels of $0.79-0.86$, the desiccated soil has a significantly lower oxygen consumption than the non-desiccated soil i.e. inversely to the aerated soil (Table 3). The other results are not significantly different. Although the comparison of the data was only possible at a small moisture gradient, but within this range RQ value for desiccated soil always equalled to 1 . RQ 1 value may appear in various situations, whereby this index reflects the total effect, resulting from a number of intermediate stages including fermentation. Perhaps the desiccation changes the pathways of fermentation processes and induces soil activity even at the moisture level at which the non-desiccated soil does not respire yet (Table 5). Probably, the difference between the desiccated and non-desiccated soil respiration rate being in conditions of oxygen deficiency consists indeed of an alteration of fermentation processes.

To sum up, we can state that under the conditions of oxygen deficiency soil respiration is significantly lower than in aerated soil. Desiccation of soil being in anoxia does not increase the use of oxygen, nor carbon dioxide emission, however the value of RQ index remains 1 . Probably the desiccation alters fermentation processes.

\section{Conclusions}

Our findings indicate that soil desiccation under unrestricted air-supply conditions, which were responsible for respiration increase (the "Birch effect"), is mainly related to aerobic respiration and is connected with a change in the amount of air in the soil. Soil desiccation increases soil respiration. After 30 days, despite further supplementation of the water it is significantly higher than the respiration of similarly watered non-desiccated soil (Table 2). Under oxygen deficit, desiccation does not increase respiration; it remains lower or not statis- 
Table 5. A comparison of the rate of oxygen consumption (OCD), production of carbon dioxide $\left(\mathrm{PCO}_{2}\right)\left(\mathrm{as} \mu \mathrm{l} \cdot \mathrm{g}[\mathrm{dm}]^{-1} \cdot \mathrm{h}^{-1}\right)$ and RQ values obtained in experiment Ma with single watering of soil samples and under conditions of air deficit, for two different variants of initial humidity: A-GWC 0.5; B-GWC 0.1. P-significance of differences between means.

\begin{tabular}{|c|c|c|c|c|c|c|c|c|c|}
\hline GWC & OCD A & OCDB & $\mathrm{P}$ & $\mathrm{PCO}_{2} \mathrm{~A}$ & $\mathrm{PCO}_{2} \mathrm{~B}$ & $\mathrm{P}$ & RQA & RQB & $\mathrm{P}$ \\
\hline range & Mean; SE & Mean; SE & & Mean; SE & Mean; SE & & & & \\
\hline $0.793-0.858$ & $0.281 ; 0.077$ & $1.405 ; 0.046$ & 0.000 & $0.281 ; 0.077$ & $0.511 ; 0.143$ & 0.189 & $1.000 ; 0.000$ & $0.363 ; 0.103$ & 0.000 \\
\hline $1.223-1.208$ & $0.383 ; 0.050$ & $0.259 ; 0.046$ & 0.103 & $0.383 ; 0.050$ & $0.509 ; 0.069$ & 0.175 & $1.000 ; 0.000$ & $2.106 ; 0.222$ & 0.001 \\
\hline $1.500-1.805$ & $1.369 ; 0.257$ & $0.000 ; 0.000$ & 0.000 & $1.369 ; 0.257$ & $0.000 ; 0.000$ & & $1.000 ; 0.000$ & & \\
\hline
\end{tabular}

tically different. However, the value of RQ index suggests that desiccation under oxygen deficit affects fermentation processes (Table 5). These explanations of these processes require further studies.

It can be assumed that the soil metabolism is affected not only by current soil moisture, but also by its initial moisture at the moment of watering (Table 2 and Table 3). The processes occurring in the well-oxygenated surface of the soil should be separately treated from those in deeper soil layers remaining under oxygen deficit. Respiration of aerated soil is always higher than the soil under oxygen deficit and remained such up to the end of the experiment, i.e. to the value of GWC of 2. However, soil respiration under anoxia equaled zero already at GWC 1.5. The value of RQ index at the moisture level lower than GWC 1 was very low attaining merely $0.3-0.4$, which suggests active fermentation processes. At higher moisture content, yet, RQ value exceeded 2 , which additionally proves that respiration was complemented by fermentation (Table 4).

\section{References}

[1] Fischer, Z. and Blažka, P. (2015) Soil Respiration in Drying of an Organic Soil. Open Journal of Soil Science, 5, 181-192. https://doi.org/10.4236/ojss.2015.59018

[2] Birch, H.F. (1964) Mineralisation of Plant Nitrogen Following Alternate Wet and Dry Conditions. Plant and Soil, 20, 43-49. https://doi.org/10.1007/BF01378096

[3] Griffiths, E. and Birch, H.F. (1961) Microbiological Changes in Freshly Moistened Soil. Nature, 189, 424. https://doi.org/10.1038/189424a0

[4] Birch, H.F. (1960) Nitrification in Soils after Different Periods of Dryness. Plant and Soil, 12, 81-96. https://doi.org/10.1007/BF01377763

[5] Dick, J., Skiba, U. and Wilson, J. (2001) The Effect of Rainfall on $\mathrm{NO}$ and $\mathrm{N}_{2} \mathrm{O}$ Emissions from Ugandan Agroforest Soils. Phyton (Austria), 41, 73-80. http://www.zobodat.at/pdf/PHY_41_3_0073-0080.pdf

[6] Dick, J., Skiba U., Munro, R. and Deans, D. (2006) Effect of N-fixing Trees and Crops on $\mathrm{NO}$ and $\mathrm{N}_{2} \mathrm{O}$ Emissions from Senegal Soils. Journal of Biogeography, 33, 416-423. https://doi.org/10.1111/j.1365-2699.2005.01421.x

[7] Bottner, P. (1985) Response of Microbial Biomass to Alternate Moist and Dry Conditions in a Soil Incubated with ${ }^{14} \mathrm{C}$ and ${ }^{15} \mathrm{~N}$ Labelled Plant Material. Soil Biology and Biochemistry, 17, 329-337. https://doi.org/10.1016/0038-0717(85)90070-7

[8] Romero-Olivares, A.L., Allison, S.D. and Treseder, K.K. (2017) Soil Microbes and Their Response to Experimental Warming over Time: A Meta-Analysis of Field Studies. Soil Biology and Biochemistry, 107, 32-40.

https://doi.org/10.1016/j.soilbio.2016.12.026 
[9] Bekku, Y.S., Nakatsubo, T., Kume, A., Adachi, M. and Koizumi, H. (2003) Effect of Warming on the Temperature Dependence of Soil Respiration Rate in Arctic, Temperate and Tropical Soils. Applied Soil Ecology, 22, 205-210. https://doi.org/10.1016/S0929-1393(02)00158-0

[10] Blažka, P. and Fischer, Z. (2014) Moisture, Water Holding, Drying and Wetting in Forest Soils. Open Journal of Soil Science, 4, 174-184. https://doi.org/10.4236/ojss.2014.45021

[11] Carter, M.R. and Gregorich, E.G., Eds. (2008) Soil Sampling and Methods of Analysis. 2nd Edition, CRC Press, Taylor \& Francis Group, Boca Raton.

[12] Grace, C., Hart, M. and Brookes P.C. (2006) Laboratory Manual of the Soil Microbial Biomass Group, Rothamsted Research.

[13] Priha, O. and Smolander, A. (2003) Short-Term Uptake of ${ }^{15} \mathrm{NH}_{4}^{+}$into Soil Microbes and Seedlings of Pine, Spruce and Birch in Potted Soils. Biology and Fertility of Soils, 37, 324-327.

[14] van Aardt, W.J. (1988) A Scholander-Type Respirometer Designed for Measuring Both Aerial and Aquatic Respiration. South African Journal of Zoology, 23, 37-41. http://www.tandfonline.com/doi/abs/10.1080/02541858.1988.11448074 https://doi.org/10.1080/02541858.1988.11448074

[15] Herbst, M., Tappe, W., Kummer, S. and Vereecken, H. (2016) The Impact of Sieving on Heterotrophic Respiration Response to Water Content in Loamy and Sandy Topsoils. Geoderma, 272, 73-82. https://doi.org/10.1016/j.geoderma.2016.03.002

[16] Jarvis, P., Rey, A., Petsikos, C., Wingate, L., Rayment, M., Pereira, J., Banza, J., David, J., Miglietta, F., Borghetti, M., Manca, G. and Valentini, R. (2007) Drying and Wetting of Mediterranean Soils Stimulates Decomposition and Carbon Dioxide Emission: The "Birch Effect". Tree Physiology, 27, 929-940.

https://doi.org/10.1093/treephys/27.7.929

\section{Submit or recommend next manuscript to SCIRP and we will provide best} service for you:

Accepting pre-submission inquiries through Email, Facebook, LinkedIn, Twitter, etc. A wide selection of journals (inclusive of 9 subjects, more than 200 journals)

Providing 24-hour high-quality service

User-friendly online submission system

Fair and swift peer-review system

Efficient typesetting and proofreading procedure

Display of the result of downloads and visits, as well as the number of cited articles

Maximum dissemination of your research work

Submit your manuscript at: http://papersubmission.scirp.org/

Or contact ojss@scirp.org 